\title{
Anatomical Variations of the Paranasal Sinuses In Chronic Rhinosinusitis
}

\author{
Ajay Kamble \\ MBBS MS(ENT), Assistant Professor, Department of Ear, Nose, and Throat Surgery, Government Medical \\ College, Chandrapur-442102, Maharashtra, India.
}

\begin{abstract}
Chronic rhinosinusitis (CRS), an extremely persistent illness, is surgically best treated by Functional Endoscopic Sinus Surgery. There are normal anatomical variants of paranasal structures, with septal deviation and concha bullosa of the middle turbinate being the most common. It is assumed that these anatomical variants contribute to chronic sinusitis by blocking normal sinus drainage.

Aim: The aim of this study was to assess the relative frequency and concurrence of variations in paranasal sinus anatomy in chronic rhinosinusitis patients.

Materials and Methods: All patients over 16 years of age referred to Department of Ear, Nose, and Throat Surgery, MGIMS, Sewagram, Wardha, Maharashtra, India, with a clinical diagnosis of chronicsinusitis were considered for this study. After excluding those with altered anatomy(iatrogenic or pathologic), scans of unaltered patients were meticulously analyzed forvariations in sinus anatomy. Findings were recorded on the patient's data sheet. All findings were analyzed, and tested with Chi square, whereapplicable.
\end{abstract}

Results: Overall 143 patients were analyzed (48.3\% male and 51.7\% female). Thefrequency of major sinus variations was: Aggernasi cell in 56.7\%, Haller cell in 3.5\%, Onodi cell in 7\%, nasal septal deviation in 63\%, andConcha bullosa in 35\%, of the studied cases.

Conclusion: The frequency of anatomic variations in sinus anatomy may be related torace and heredity. A lower number of cases in addition to the use of low yield imagingmay explain the discrepancies observed between our results and other investigations.

The findings of the present study were based on computed tomography.

Keywords: Anatomy; Sinus; Anatomic variation; Sinus; CT scan; Conchabullosa

\section{Introduction}

Computed tomographic (CT) scanning of theface has become a standard part of oromaxillofacialimaging. Variations in paranasalsinus anatomy as shown on CT scans is ofpotential significance, for it may pose risksduring surgery or predispose to certainpathologic conditions and diseases. Studyingthe relative frequency and concurrence ofthese variations in a given population, andcomparing the results with that of other racesmay yield important hints in medical decisionmaking and surgical planning for all patients[1,2]. In this studythe anatomic variations of the paranasal sinuswere assessed by means of CT scans inpatients referred to Department of Ear, Nose, and Throat Surgery, MGIMS, Sewagram, Wardha, Maharashtra, India.

\section{Materials And Methods}

All patients aged 16 years and over,successively referred to Department of Ear, Nose, and Throat Surgery, MGIMS, Sewagram, Wardha, Maharashtra, India, over a 6months period (April through September 2013) with a clinical diagnosis of chronicsinusitis were considered for this study. Sincethe aim of our study was to evaluate normalvariations, cases found to harbor nasopharyngealtumors, polyps, gross mucosalhypertrophy, previous surgery of the face, andcopious discharge or fungal masses extensiveenough to distort or obscure the regionalanatomy were excluded from the study. Altogether, images were collected from 143subjects with unaltered anatomy. All CT scanswere obtained on the spiral scanner beginningat the glabella and terminating at the mostdorsal point of the sphenoid sinus (i.e., dorsumsella). As a standard, slice thickness andinterval were set at 5 and $2 \mathrm{~mm}$ respectivelyfor all sites. Anatomical findings of each subjectwere meticulously scrutinized and recorded onthe patient's data sheet. The identifiedvariations included:

- Aggernasi cell, i.e. the most anterior

ethmoid air cell located on the lateral nasalwall and anterosuperior to the hiatusseminularis.

- Onodi cell: the most posterior ethmoid aircell with posterior and lateral extensions.

- Haller cells which are ethmoidal air cellsextending along the medial roof of themaxillary sinus.

- Concha bullosa an anatomic variation

manifesting as aeration of the middle turbinate(it may also occur in the superior and inferiorturbinates, with far less frequency). 
- Septal deviation i.e., asymmetric nasal septum position that can force nasal turbinateslaterally [1].

\section{Results}

The study group consisted of 143 subjects( $48.3 \%$ male, $51.7 \%$ female), with a mean ageof 35.27 years, ranging from 16 to 75 years. The frequency of variations in paranasal sinusanatomy in our patient sample was as follows:

- Aggernasi cell (56.7\%) [Fig 1], with $17.5 \%$ on theright, $7.7 \%$ left and $31.5 \%$ of all patientshaving Aggernasi cell as a bilateral finding.

Nasal septal deviation was found in $63 \%$ of which $28.0 \%$ deviated to the right and $31.5 \%$ to the left. Bilateral deviation was observed in $3.5 \%$ of all cases.

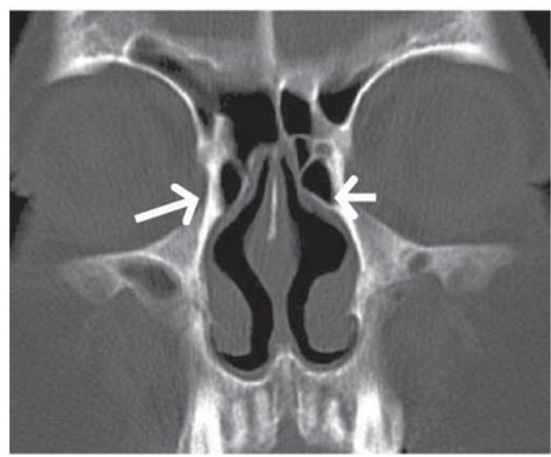

Fig. 1 Coronal CT scan shows bilateral anterior ethmoid air cells lying deep to lacrimal bone and bordering floor of frontal sinuses (Aggernasi cell).

- Haller cell occurred in 3.5\% of all subjectswith $1.4 \%$ on the left and $2.1 \%$ bilateral; nonewere observed on the right side [Fig 2]

- Onodi cell appeared on $7 \%$ of the scans with $2.8 \%$ on the right, $0.7 \%$ left and $3.5 \%$ locatedbilaterally.

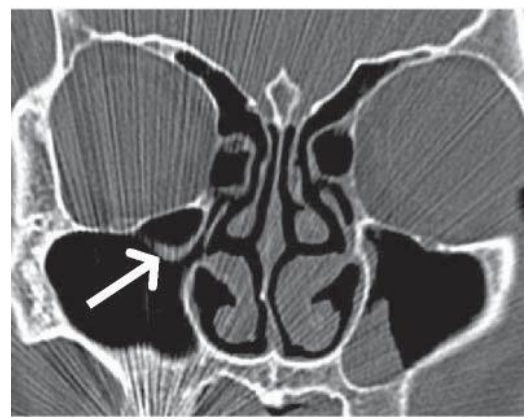

Fig. 2 Coronal CT scan shows pneumatizedethmoid air cell that projects along the medial roof of right maxillary sinus and most inferior portion of lamina papyracea(Haller cell).

- Conchabullosa was found in $35 \%$ of thesamples [Fig.3]. Of these, $11.9 \%$ were on the right, $11.2 \%$ left and $11.9 \%$ occurred as a bilateralanatomic variation.

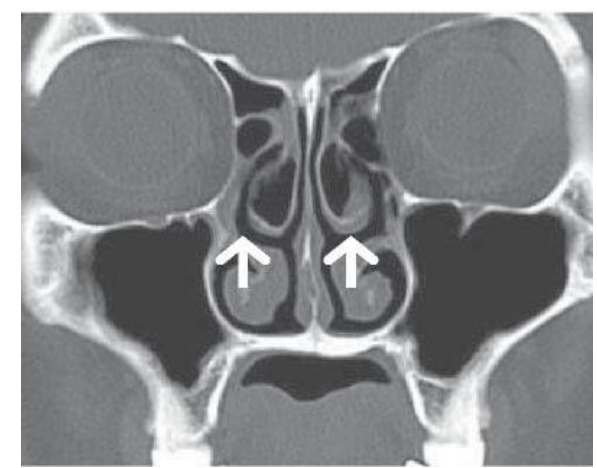

Fig. 3 Coronal CT scan shows pneumatizationof middle turbinate bones bilaterally (concha bullosa). 


\section{Discussion}

In the current study, Aggernasi cells werefound in $56.7 \%$ (right, left and bilateral puttogether) of the cases. Kantarci et al. reportedthis anatomic variation in 47\% [2],Messerklinger in 10-15\% [3], Davis in 65\%[4] and Van Alyea in 89\% [5] of their subjects. The frequency of Aggernasi cell in our studypopulation is similar to that of Kantarci andDavis, but differs from the results obtained byVan Alyea and Messerklinger. This differencemay be explained by the fact that Van Alyea etal tried to locate this anatomic variation on theethmoid bone probably because CT scansweren't available during the 1930s.Messerklinger made most of his observations on conventional radiography, therefore alsofailed to verify most of these air cells. Theclinical importance of Aggernasi cell has beendefined by Brunner et al in 1996. They showedthat the cell and its extensive pneumatizationwith consequent narrowing of the frontal sinusostium is the main and clinically significantcause of persistent frontoethmoid pain and chronic frontal sinusitis. It was also stated thatthe dimensions of the Aggernasi cell is largerin patients who suffer from frontal sinusitis[6].

Haller cell which only seen bilaterally on theleft side, occurred in only $3.5 \%$ of the scansstudied in the present investigation (in none ofthe cases occurred on the right side). Kantarci [2] andSarna [7] reported the frequency ofHaller cell $18 \%$ and $10 \%$ respectively. Sivaslimentioned Haller cell as the 3rd most commonnormal anatomic variation in his sample [8]. The results of the present study are in accordance with others in that the Haller cell isan infrequent finding among the variations inparanasal sinus anatomy. The remarkably high(18\%) occurrence of this cell in Kantarci'sreport is because of the large sample size usedin the study (overpowering effect) [2]. Theclinical importance of Haller cell is itsimplication in sphenoid sinusitis which wasdescribed by Alho in 2003 [9]. He reported theexistence of a large Haller cell can bepredictive of sinusitis.

Onodi cell was found in 7\% (2.8\% right, $0.7 \%$ left and 3.5\% bilateral) of the patientsparticipating in the current study. Other studiesreported Onodi cell in 8\% [10] and 0\% [2] oftheir samples. Sivasli also reported Onodi cellas a rare anatomic variation [8]. Our resultssupport other investigations in defining Onodicell as a rare anatomic variation. A numericaldifference is observed between our findingsand Kantarci's results. The sample size usedby Kantarci was much larger than the one usedin the present study; if our sample size hadbeen increased, the difference might turn outto be significant which could probably beexplained by racial, geographic and hereditarydifferences. Onodi cell is the most posteriorethmoid air cell that extends laterally. Thisextension is near the carotid canal and close tothe optic nerve, which emphasizes the clinicalimportance of considering this anatomicvariation prior to any attempt for invasiveintervention. The surgeon must pay closeattention to the occasional Onodi cell inpreoperative evaluation to avoid potentialcomplications of endoscopic sinus surgery. Therefore it would seem logical to assume thatrhinogenic optic neuritis and Onodi cell arerelated findings.

Nasal septal deviation was found in 63\% (28.0\% right, 31.5\% left and 3.5\% bilateral) ofthe studied cases. Sarna reported septaldeviation in $20 \%$ of his subjects [7].Considering that Sarna's investigation wasconducted on a larger number of cases, apossible explanation for the higher frequencyof nasal septal deviation in our populationmight be because of difference in the Persianrace. Nasal septal deviation has an importantrole in causing sinusitis and complicationsduring endoscopic sinus surgery. Asymmetricnasal septum position also can force nasalturbinates laterally and result in narrowing ofthe middle meatus and ultimately blockingdrainage of the ipsilateral maxillary, anteriorethmoid and frontal sinuses. Concha bullosa, was found in $35 \%$ of thestudied subjects, $11.9 \%$ on the right, $11.2 \%$ left and $11.9 \%$ as a bilateral anatomicvariation. Sivasli reported Concha bullosa asthe most frequent anatomic variation amonghis patients [8]. Cochabullosa is associatedwith inflammation of the anterior ethmoid aircells and the maxillary sinus. Interstingly, asignificant correlation was found betweennasal septal deviation and the contralateralConcha bullosa $(\mathrm{P}=0.009)$, in the presentstudy; i.e. if the Concha bullosa is on the right,the nasal septum tends to deviate to the leftand vice versa.

\section{Conclusion}

Nasal septal deviation was the most common anatomical variation followed by concha bullosa potentially associated with chronic rhinosinusitis. A lower number of cases in addition to the useof low yield imaging may explain thediscrepancies observed between our resultsand other investigations. The findings of thepresent study were based on computedtomography.

\section{References}

[1]. Cumings Charles, Fredrickson John, HarkerLee, Krause Charles. Otolaryngology Head \&Neck Surgery. 3rd ed. Missouri: Mosby; 1998;p:1059-1092

[2]. Kantarci M, Karasen RM, Alper F, Onbas O,Okur A, Karaman A. Remarkable anatomic variationsin paranasal sinus region and their clinicalimportance. Eur J Radiol2004;50(3):296-302

[3]. Messerklinger W. On the drainge of the normalfrontal sinus of man.ActaOtolaryngol 1967; 63:176-81

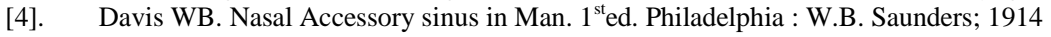

[5]. VanAlyea OE. Ethmoid labyrinth anatomicstudy with consideration of the clinicalsignificance of its structural characteristics. ArchOtolaryngol 1939; 29: 881-901

[6]. . Brunner E, Jacobs JB, Shpizner BA, LebowitzRA, Holliday RA. Role of the aggernasi cell inchronic frontal sinusitis. Ann OtolaringolLaryngol1996; 105(9): 694-700. 
[7]. Sarna A, Hayman LA, Laine FJ, Taber KH.Coronal imaging of the osteomeatal unit: anatomyof 24 variants. J Comput Assist Tomogr 2002; 26(1): 153-7.

[8]. Sivasli E, Sirikci A, Bayazyt YA, GumusburunE, Erbagci H, Bayram M, Kanlykama M.Anatomic variations of the paranasal sinus area inpediatric patients. SurgRadiolAnat 2003;24(6):400-5.

[9]. Alho OP. Paranasal sinus bony structures andsinus functioning during viral colds in subjectswith and without a history of recurrent sinusitis.Laryngoscope 2003; 113 (12): 2163-8.

[10]. Stammberger HR, Kennedy DW. Paranasalsinuses: anatomic terminology and nomenclature.The anatomic terminology group.Ann OtolRhinolLaryngolSuppl 1995; 167: 7-16. 